\title{
A journey of a thousand miles begins with one small step - human agency, hydrological processes and time in socio-hydrology
}

\author{
M. W. Ertsen ${ }^{1}$, J. T. Murphy ${ }^{2,3}$, L. E. Purdue ${ }^{4}$, and T. Zhu ${ }^{1}$ \\ ${ }^{1}$ Delft University of Technology, Water Resources Department, Delft, the Netherlands \\ ${ }^{2}$ Argonne National Laboratory, Argonne, USA \\ ${ }^{3}$ University of Chicago, Computation Institute, Chicago, USA \\ ${ }^{4}$ School of Sustainability, Arizona State University, Tempe, USA \\ Correspondence to: M. W. Ertsen (m.w.ertsen@tudelft.nl) \\ Received: 4 November 2013 - Published in Hydrol. Earth Syst. Sci. Discuss.: 21 November 2013 \\ Revised: 26 February 2014 - Accepted: 28 February 2014 - Published: 8 April 2014
}

\begin{abstract}
When simulating social action in modeling efforts, as in socio-hydrology, an issue of obvious importance is how to ensure that social action by human agents is wellrepresented in the analysis and the model. Generally, human decision-making is either modeled on a yearly basis or lumped together as collective social structures. Both responses are problematic, as human decision-making is more complex and organizations are the result of human agency and cannot be used as explanatory forces. A way out of the dilemma of how to include human agency is to go to the largest societal and environmental clustering possible: society itself and climate, with time steps of years or decades. In the paper, another way out is developed: to face human agency squarely, and direct the modeling approach to the agency of individuals and couple this with the lowest appropriate hydrological level and time step. This approach is supported theoretically by the work of Bruno Latour, the French sociologist and philosopher. We discuss irrigation archaeology, as it is in this discipline that the issues of scale and explanatory force are well discussed. The issue is not just what scale to use: it is what scale matters. We argue that understanding the arrangements that permitted the management of irrigation over centuries requires modeling and understanding the small-scale, day-to-day operations and personal interactions upon which they were built. This effort, however, must be informed by the longer-term dynamics, as these provide the context within which human agency is acted out.
\end{abstract}

\section{Introduction}

Simulating social action is a rising field of study. Based on detailed, empirical study and specific understanding of both human actions and networks in society, more elaborate models are being constructed. An issue of obvious importance is how to ensure that social action by human agents is wellrepresented in the analysis and the model; this issue is of vital importance for socio-hydrology as well. Although not necessarily so, in general one can find two responses to the question of how to represent human agency. In the first one, human decision-making - if considered at all - is modeled on a yearly basis; in the second one, human agency is lumped together, assuming that collective social structures - states, companies, but also social class or gender - provide an adequate framework representing human decision-making. We argue that both responses are problematic.

Humans make decisions every day and not once a year, and even the once a year decisions (where to go on holiday for example) are not made once a year, but are more to be seen as a series of decisions. Clustering humans into organizations is problematic as well, as these organizations themselves are the result of agency, and clustering usually means associating certain predefined features to those entities. Those features will usually also be the result of the model, and as such we have a problem of circularity. Please note that we do not argue that social structures do not exist, as anyone studying society would recognize that certain hierarchies, arenas and institutions do exist. We do argue, however, that these social 
structures can never be used as explanatory forces for processes we observe.

Comparable dangers can be expected for socio-hydrology, if it is not done carefully. The short-term effects of hydrology on humans and the actions of humans to counter those which in turn affect hydrology and so on need to be included in the model. This means allowing for time patterns of wet years and dry years, abundant crop yields and crop failures, times of economic prosperity and depression, shifts in the dominant politics, major storms, etc., and most of all how these patterns overlay one another. Short-term memories have a major impact on water resources use by individuals and management policies by administrators.

We argue that there are two feasible ways out of this issue, or two levels of modeling that we can do relatively safely; we will develop some more specific ideas about one of them. The first way out of the dilemma of how to include human agency is essentially to ignore it completely and to go to the largest societal and environmental clustering possible: society itself and climate, with a reasonable time step of years or decades, to determine links between the two to test certain theories and define/find/test analogies. We will not develop this idea further, as it is discussed in the contribution of Pande and Ertsen to the SI in HESS-D (Pande and Ertsen, 2013).

The other way, and the one we will develop further in this paper, is to face human agency squarely. To do so we direct our modeling approach to the human agency of individuals - arguably the lowest possible scale that could be called a "social" approach - and couple this with the lowest appropriate hydrological level and time step: daily or hourly rain and/or flow. With this approach we can employ our models to ask under which cultural-organizational constraints model outcomes are supported by our data. This detailed modeling predefines as few cultural aspects as possible in the human agents; instead it treats cultural aspects as constraining contexts for the model, which itself is based on actions and materiality. Personal relationships, in networks and institutions, are outcomes of the model's operation.

This second approach is supported theoretically by the work of Bruno Latour, the French sociologist and philosopher. Latour argues that human decision-making and development of societal institutions is a local activity and constructed within networks of actors (Latour, 2005). These networks are continuously created and recreated by human actors engaging with other human actors and non-human intermediaries. Actor-networks are to be understood as a unit, without preliminary definitions of what is "inside" or "outside" of, or "local" or "context" about a network. Networks are created through human agency engaging with other human agents and material realities (like roads and rain); studying networks with any pre-suggested division in terms of levels, contexts or relations needs to be avoided. The resulting networks link short- and long-term human responses, from individual to societal level, to water flows and their stochastic natures on scales as different as flows in hours to volumes per year, decade or even century.

In this paper we discuss how such a focus on the shortterm, small-scale interactions among people with(in) their environment can be developed. We focus our discussion on irrigation systems, and specifically on studies within archaeology, as these studies provide data sets that allow linking short term to long term. Irrigation is complex, due to feedbacks between material environment - the water source and humans. Because of the highly detailed and complex relations between human actions and the social and material context in irrigation, it is extremely difficult to develop a well-suited scientific approach to model it. Not only do we need to understand the effect of material conditions on human actions but we also need to understand how human agency is linked to rules within irrigation systems. As such, irrigation is a clear - if not one of the best - example of sociohydrology.

Perhaps paradoxically, archaeological examples are useful for this discussion because the archaeological record, with respect to many things we might wish to know, is incomplete. The lacunae in our knowledge impinge on our modeling efforts in a way that brings questions of scale to the fore: we are forced to choose abstractions, and so must choose them carefully. Likewise we are also asked to consider questions that we might like to answer against data that we have available, and so to consider some approaches to be provisional or hypothetical. The outcome is what Murphy (2009) termed an "exploratory" approach. Two key components of this are the obligation to ask what components are required and the concomitant freedom to discard those that are not. The issue is not just what scale to use: it is what scale matters. Our contention in this paper is that identifying and understanding the arrangements that permitted the management of large-scale irrigation works, even those that persisted over centuries, requires modeling and understanding the small-scale, day-today operations and personal interactions upon which they were built. This effort, however, must be informed by the data from longer-term studies, for the longer-term dynamics provide the context within which our object of study, human agency, is acted out.

\section{Agent-based models as the way forward?}

Irrigation systems are spatial assemblies of built elements supplying crops with water. System's operation is a mixture of physical distribution facilities that bring water to fields and crops, and socio-political coordination between the different actors that use the water flows. Irrigated agriculture is more than managing volumes each month or season; it is typically about manipulating flows of water in time periods as short as hours and days. Such short-term manipulations result in water balances and volumes on larger temporal and spatial scales. Those lumped volumes and balances cannot be used, 
however, to derive the many small-scale manipulations of water flows that built the lumped results: reading back the detail from the general is impossible (Ertsen, 2010; Ertsen and Van der Spek, 2009).

With their many entities, their interactions within a changing environment, and the resulting emergent properties, irrigation systems are typical of systems for which agent-based modeling $(\mathrm{ABM})$ yields fruitful analysis. The application of $\mathrm{ABM}$ by creating software agents to play the role of irrigation users and managers is a straightforward use; modeling the daily interactions of such agents together with the water fluxes is still in development, but promises better understanding of irrigation systems as anthropogenic landscapes. Those landscapes are the result of many individual activities - on their own or within entities like households and social groups - within the physical boundaries (hydraulic and hydrological) of the irrigated areas (Ertsen, 2012a, b).

Agent-based models have been applied successfully in rain-fed agriculture. Although far from being simple, rainfall can be assumed to be available for all agents: actions by agents do not affect water availability of other agents. In most studies on irrigation systems, an analogue reasoning is implicitly assumed: water availability is an input just like rain from the sky. For example, Altaweel (2008) concluded that in northern Mesopotamia irrigation promoted stable yields. He does, however, represent water availability as a $150 \mathrm{~mm}$ water gift, as if the water came out of the sky like rain. There is no guarantee, however, that the irrigation system could actually deliver water equally to all farmers, for hydraulic and/or social reasons. Compared to rain-fed agriculture, irrigation is complex, with extra feedbacks between environment and humans. This requires detailed understanding of daily realities in irrigation. Water availability along canals is a result of human agency - including stealing, struggle and cooperation - affecting actual flows through time and space, and cannot be assumed to be equal. This makes agent-based modeling in irrigation a major challenge.

To use ABM in understanding how socio-hydrological reality emerges from purposeful, (un)coordinated activities of individuals and small groups in irrigation systems, a fundamental issue related to human action needs to be solved: the time step in the analysis. This may seem a trivial modeling question, but is actually a fundamental one for human agency. Assume a canal with a user taking water and then closing his gate. This causes a changing water flow to a user downstream, who may not want this extra water and closes his own gate. Actions of this upstream user cause - through actions of a downstream user - changing situations upstream. If this took only a few hours, analysis based on a time step of 1 day misses this action-reaction. However, social relations between users may be ruined: "If you steal my water today, I will hate you tomorrow". Or, to put it more politely: "I may not want to maintain the canal in cooperation with you next month or year". If this is our concern, then arguably we should not explain how irrigation-based societies collapsed after centuries or even millennia, but why these societies did not collapse each and every day.

Irrigation systems are highly dynamic systems, and human-induced patterns in irrigation are often idiosyncratic and unpredictable. However, they can be studied systematically. In recent work, Ertsen (2010, 2012a, b) shows how interactions between humans, hydrology and hydraulics within irrigation systems create patterns of water use, and provides the basic modeling methodology to study these interactions. This approach is explicitly based on the physical processes creating surface and subsurface water fluxes. Substantial progress can be made by including a detailed analysis of material conditions and changes related to human agency, especially accounting for the new material conditions of irrigation systems created by human actions. Human agency may be restricted by material conditions of an irrigation system, with certain actions not possible or more difficult to achieve, but in reality humans still make the key decisions in water allocation, system management and irrigation development. Human agency, hydrological processes and hydraulic variables create irrigation together. Combined modeling of daily interactions between human agency and water fluxes will increase our understanding of irrigation systems as anthropogenic landscapes, and how they emerge from socioeconomic and environmental contexts.

Our discussion here presents three archaeological views of components of an irrigation system. Our examples are drawn from studies in the semi-arid American Southwest (Arizona), where irrigation has allowed farmers to cope with environmental constraints and grow crops for more than two millennia. The three views are presented as examples of long-term, medium-term, and short-term scales as revealed through archaeology and related studies. Ideally we would present a single, integrated picture that covers a single, unified example. In fact, the examples we choose here, though related, are separate. The progress of archaeological research could eventually provide a unified and complete picture of the entire region, but for now we present them as examples - including their methodological details - to support our contention that an integrated view is both possible and necessary for the rich understanding we seek of how irrigation systems, including the social relationships and institutions that arise from and support them, are shaped - or, better, are made and continually re-made via human agency - through time.

\section{Climate reconstructions: the archaeological long-term view}

Irrigation systems are situated in a specific hydrological environment. In this paper, we focus on the desert environment of central and southern Arizona, an area rich in diverse plant life (Fish, 1989) that supported some of the largest irrigation works in the prehistoric New World. The Hohokam society, that persisted for a millennium between 
AD 450 and 1450 (Bayman, 2001; Fish and Fish, 2007; Gumerman, 1991), built extensive canals that drew water from the Gila River (and its tributaries) and the Salt River in central Arizona and the Santa Cruz River in Southern Arizona. Archaeological research on these canals has been extensive, but has focused on more readily available information about large-scale canal networks, their organization and the paleo-environmental signature they record (e.g., Howard, 1993; Howard and Huckleberry, 1991). Investigation into the day-to-day operation of these systems at the field level has been limited or drawn from abstract scenarios (Murphy, 2009, 2012) rather than archaeological data, which have not previously been available. Below we will discuss what data sets are available and how these could be used for the detailed, short-term modeling efforts we propose.

We start with climatic issues. Irrigation is an attempt to modify the hydrological cycle and change its direct impact; the short-term impacts on irrigation and nature of hydrological features are important to consider when studying irrigation management. One of the challenges of doing so is to determine the variability of hydrological features like temperature and available moisture. In other words, how do we obtain a similar record of climatic variability as the measurements we have today? As an illustration of how a useable paleoclimatic data set can be achieved, we calculated the monthly temperature/precipitation in our (lowland) study area in Arizona. We used reconstructed climatic data based on tree rings, of the kind that archaeologists in the US Southwest have been building for decades. Climate reconstructions based on tree-ring proxy records have been considerably utilized, in large part because of their relatively high resolution and reliability (Kohler, 2012).

In the selection of potential tree-ring indexed series, we considered four principles: (1) the tree-ring sites should be relatively close to the study area; (2) the tree ring should be distinctively sensitive to climatic variables (temperature and precipitation); (3) the data set should cover the main period one is interested in (which would be AD 450-1450 for the main Hohokam period); (4) and the data set should correlate with the study area. Based on the first three principles, we selected the data from Salzer and Kipfmueller (2005), which cover annual precipitation (in October-July) for a 1425 year period (AD 570-1994) and annual mean-maximum temperature for a 2262 year period (AD 250 BC-1997), based on calibrated precipitation series with data from NOAA Climate Division 2 (CD2) and temperature series with data from Fort Valley research station. There are three tree-ring chronologies in the lower forest border of Arizona (Flagstaff, Canyon de Chelly, and Navajo Mountain) being used for precipitation reconstruction and one in San Francisco Peaks in northern Arizona (Flagstaff) for temperature reconstruction, as shown in Fig. 1.

We were able to meet the fourth principle by linking the monthly observed data in the lowlands and the difference/ratio between yearly reconstructed tree-ring data and

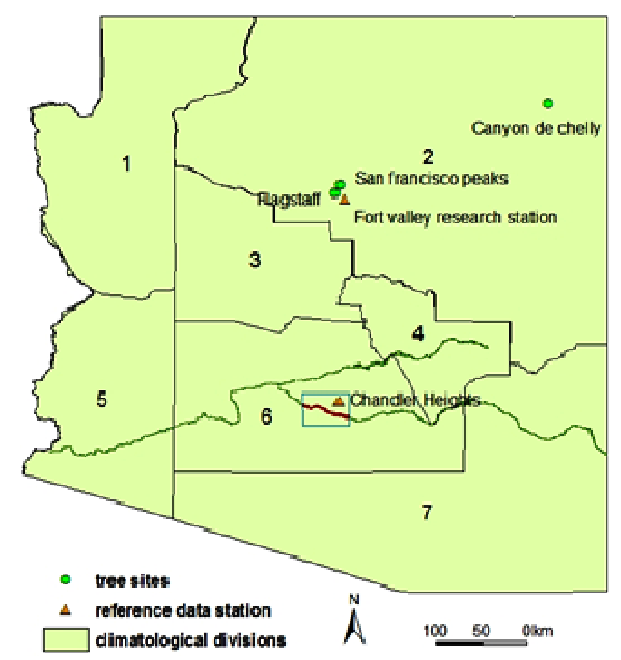

Fig. 1. Location of sites in Arizona for which tree-ring chronology is available.

yearly observed data in the uplands. We assumed this a feasible approach as climate variability in upland and lowland Arizona are highly correlated. Obviously, we have to assume that climatic variability has not changed over time, to be able to include the observed data in the analysis. At the moment, there seems to be no way out of this assumption. Furthermore, the 1000 years of tree-ring data series shows no evidence indicating climate changes in the uplands. Using this approach, two issues need to be dealt with: the altitudes of the tree sites, and the timescale of the data (see also Ni et al., 2002).

Starting with the first issue, the tree sites used for treering-based analysis and our Hohokam irrigated area are not on the same altitude. All tree-ring sites are located at a high altitude of above $2000 \mathrm{~m}$, while the Hohokam area is situated around $450 \mathrm{~m}$ a.s.l. (above sea level). Associated with this is the climatic zoning: tree-ring sites are found in the CD2 zone, characterized by low temperatures and relatively substantial rainfall, whereas the Hohokam main area is within the CD6 zone, with a hot and dry climate. We basically used a straightforward correlation between temperature and rainfall for the two zones to reconstruct the annual data for the lowland area (Fig. 2). Precipitation data from zone CD6 and temperature data from Chandler Heights in the same area were used as reference data. We then correlated tree-ring precipitation data between zones CD6 and CD2 and temperature data between Chandler Heights and Fort valley. The correlation coefficient $r$ for temperature was 0.99 , which was higher than the coefficient for precipitation of 0.83 . We concluded that both rainfall and temperature in our study area were strongly correlated with data from the tree site zone.

The second issue of timescale related to the need to have a time series of rainfall and temperature data at a finer scale than the annual tree-ring chronologies (based on the 

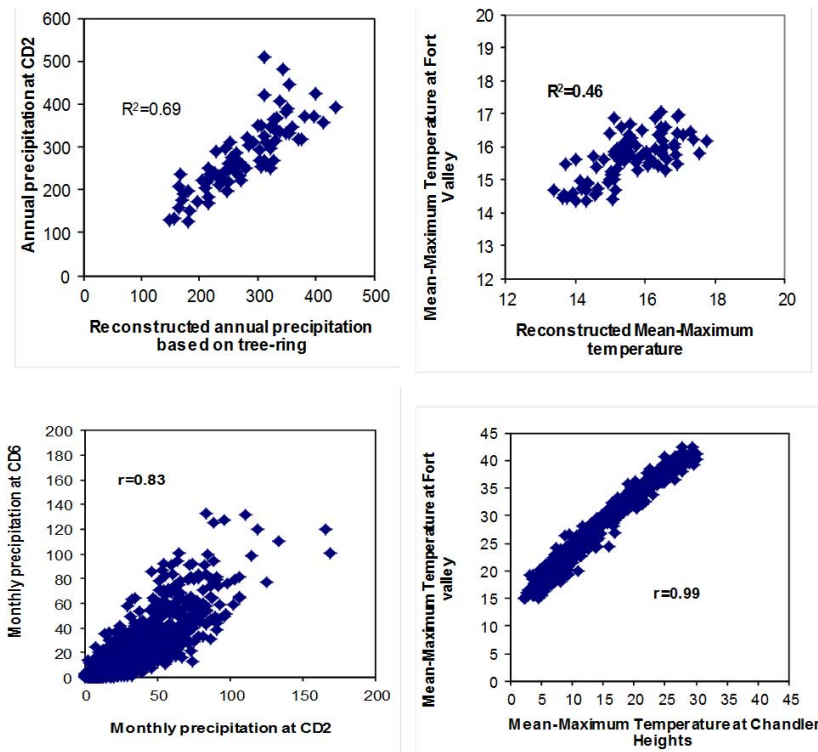

Fig. 2. Statistical analysis on tree sites between observed and reconstructed temperatures and precipitation, as well as observed data between tree sites and study area (data sources: NOAA).

October-July season). In order to allow using climatic data on a meaningful scale to simulate crop productivity and water use, data on at least a monthly scale are required. As such, we needed to downscale the annual data into that of monthlyscale. For this downscaling, we used the climate factor (CF) method (Chen et al., 2011), which adjusts observed time series by adding the difference (for temperature) or multiplying the ratio (for precipitation) between future and present climates. One of the advantages of the CF method is its straightforward application. Most CF methods are used for forecasting climatic variables, by computing the changes between a baseline and future scenario. For our own historical application, we modified the equations slightly by linking the change factors that are between reconstructed tree-ring data and upland observed data. As such, the CF method could take into account climatic differences between high and low altitudes, by linking climate variability at high altitudes to the same in the lowland, along the equations shown below.

$T_{\text {dow,stu,m }}=T_{\text {obs,Cha,m }}+\left(\bar{T}_{\text {recon.,y }}-\bar{T}_{\text {obs,Fort,y }}\right)$
$P_{\text {dow,stu,m }}=P_{\text {obs,CD6,m }} \times\left(\bar{P}_{\text {recon.,y }} / \bar{P}_{\text {obs,CD2,y }}\right)$

$T_{\text {dow,stu,m }}$ is the downscaled monthly temperature for the study area. $T_{\text {obs,Cha, } m}$ is the observed monthly temperature at Chandler Heights in the reference period. $\bar{T}_{\text {recon.,y }}$ is the reconstructed yearly temperature based on tree-ring data. $\bar{T}_{\text {obs,Fort,y }}$ is the observed yearly temperature at Fort Valley Station in the reference period. $P_{\text {dow,stu,m }}$ is the downscaled monthly precipitation for the study area. $P_{\mathrm{obs}, \mathrm{CD} 6, \mathrm{~m}}$ is the observed monthly temperature for CD6 in the reference period. $\bar{P}_{\text {recon.,y }}$ is the tree-ring reconstructed yearly temperature.
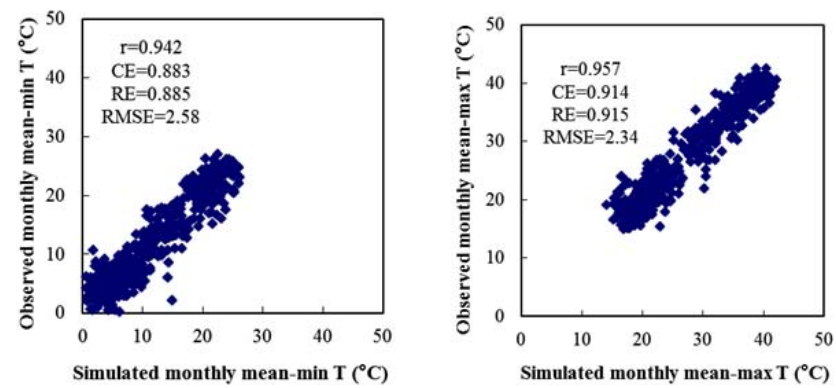

Fig. 3. Statistical validation of reconstructed temperatures based on the correlation between simulated and observed temperatures.

$\bar{P}_{\text {obs,CD2,y }}$ is the observed yearly temperature for $\mathrm{CD} 2$ in the reference period.

The observed monthly data from our study area (Chandler Heights and CD6) were used as adjusting data. The reference periods cover 50 years for both precipitation (ca. 1896-1945) and temperature (ca. 1909-1958). The adjusting series are randomly selected from the reference period. On the corresponding period, the difference or ratio between reconstruction and observation data of tree sites are calculated and given to the adjusting series. Figure 3 shows a high positive correlation $(r)$ between simulations and observations. The validation reduction of error statistic (RE) reaches 0.885 and 0.915 in mean-minimum temperature and mean-maximum temperature, respectively. The high positive value indicates that the model performs a good reconstruction for the whole simulation period, and better than in the calibration period. The root mean square differences (RMSD) between simulation and observation are 2.34 and 2.58 , respectively.

The simulated series of precipitation were validated by comparing its month-distribution percentage with the observations for the same percentage. Both measured and simulated series from 1896 to 1987 were classified into 4 bins according to the water-year precipitation of $0-25,25-50,50-$ 75 , and $75-100 \%$. Then, the proportions of each month's precipitation within the whole year were calculated for observation and simulation, respectively. Finally we compared those percentages for simulation and observation. Figure 4 suggests the downscaled methodology basically represents a good match for the rainfall frequencies of 0-25 and 25-50\%. For the 50-75\% category, representation in January, February, July and August is less good. During dry years (75$100 \%$ ), the model performed very well over the whole year. In general, the model captured the precipitation frequency at monthly scale well.

We would, of course, like to pursue this picture into even finer detail; this is especially true because the Gila River was rather complex (see Graybill et al., 2006). A next step would be to link stream flow in the Gila River to the rainfall data. Unfortunately, the data needed to support this are lacking: direct flow data exist beginning with the installation 

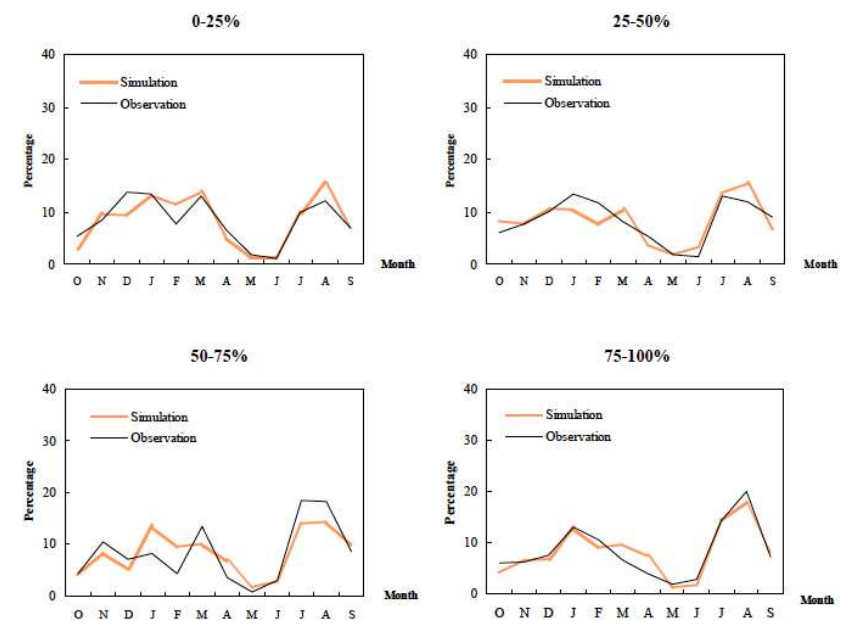

Fig. 4. Validation of simulated precipitation series using monthdistribution percentage.

of the Kelvin gauge in 1911, but by then upstream diversions for irrigation had already significantly reduced flow (Huckleberry, 1999); in 1928 construction of the Coolidge Dam virtually eliminated flow except during extreme flooding periods. It would be of great value to have stream flow data for longer periods; nevertheless, the reconstructions presented here open a wide array of lines of inquiry about the long-term trajectory of the practice of irrigation, and present the backdrop for the middle- and short-term views we will take in the next sections.

\section{Canal system geo-archaeology and micromorphology: the medium-term view}

The study of past irrigation systems has traditionally been integrated in the field of theoretical anthropology, ethnography and archaeo-geography (e.g., Hunt and Hunt, 1973; Gentelle, 1980). Hydraulic systems appear as structural elements of the socio-political organization of communities and their territory on various temporal and spatial scales. Past irrigation systems however can also be studied from a socio-environmental perspective using a geo-archaeological and chronological approach (Berger, 2000). Canals are considered as technical systems on one side, with their own temporalities, from their construction, maintenance to their abandonment. On the other side, their fill records environmental fluctuations (floods, water stagnation, rhythmic flow to down-cutting events and fluvial morphological change). Depending on the initial research question, irrigation structures and systems can be perceived at various spatial scales (main, secondary or tertiary canal; irrigation system; geomorphic unit) and temporal scales (short-term events; phases of cultural stability/breakdown). As the aim of this paper is to understand short-term socio-environmental interactions, we will focus here on the methodological keys to study individual structures in the field and laboratory. One main Hohokam canal located along the Salt River in the semi-arid Phoenix Basin will be used as an example (Fig. 5a).

Aerial photographs and old maps usually provide information on the location of past irrigation systems. In the Phoenix Basin in Arizona, 20 years of salvage archaeology have enabled researchers to build a massive database of irrigation systems (Fig. 5a) (Howard and Huckleberry, 1991) (see also Midvale, 1966). The main Canal System 12 (CS12) (Fig. 5a and b), which is the most downstream system of the valley, was studied in 2007 in the framework of a salvage archaeology project directed by Soil System Inc. at the site of Cashion, a Hohokam village occupied from the 7th to 12th century AD. CS12 was encountered 3 miles downstream from its head gates, nearly $2.5 \mathrm{~m}$ below the surface; four trenches were dug to study its fill and reconstruct its functional history (Fig. 5b). The fill was very well preserved, and three superposed canals were identified, the base of the bottom one being separated from the upper one by more than one meter of sediments (Fig. 6). Once the canal profiles were exposed, systematic criteria were described: canal shape, description of the sedimentary fill (texture, structure, color, inclusions, etc.), visible traces of human management (canal curing based on stratigraphic unconformities (Fig. 5c), stone, earth walls or fine material on the sides and bottom of the feature to protect it from erosion).

First interpretations, such as the occurrence of flooding events, episodes of water stagnation, local erosion or canal abandonment, traditionally identified based on texture (sand versus clay), sediment structure and sorting (graded deposits versus weakly sorted sediments, inclusions) need to be put forward with precaution. First, the canal studied should be understood within its network. Smaller canals downstream in a system will record different information than canals closer to the head gates. Second, sedimentary signatures might have multiple origins. The origin of this difference (natu$\mathrm{ral} /$ anthropic) is difficult to estimate, but parallel studies on connected main, secondary, tertiary canals and associated irrigated fields can provide a complete reconstruction of human management and the significance of flow at the scale of a system (e.g., Purdue et al., 2010, 2014). Also, building references in historic and modern canals, for which we have better chronological frames as well as written data on human activity and fluvial dynamics, could help better discuss this issue of equifinality (e.g., Huckleberry, 1999; Purdue, 2011).

Irrigation structures need to be dated and connected to a hydrological and cultural context. This is probably the most complex step, even more when high-resolution data on flow is needed. As irrigation structures start to fill with sediments right after their construction, dates processed at the bottom of the structure will provide an idea of when the structure was built, while a date in the upper part of the fill will indicate when the structure was abandoned. However, canals are anthropic structures, frequently maintained, and parts of the fill are often removed. Ideal situations occur 


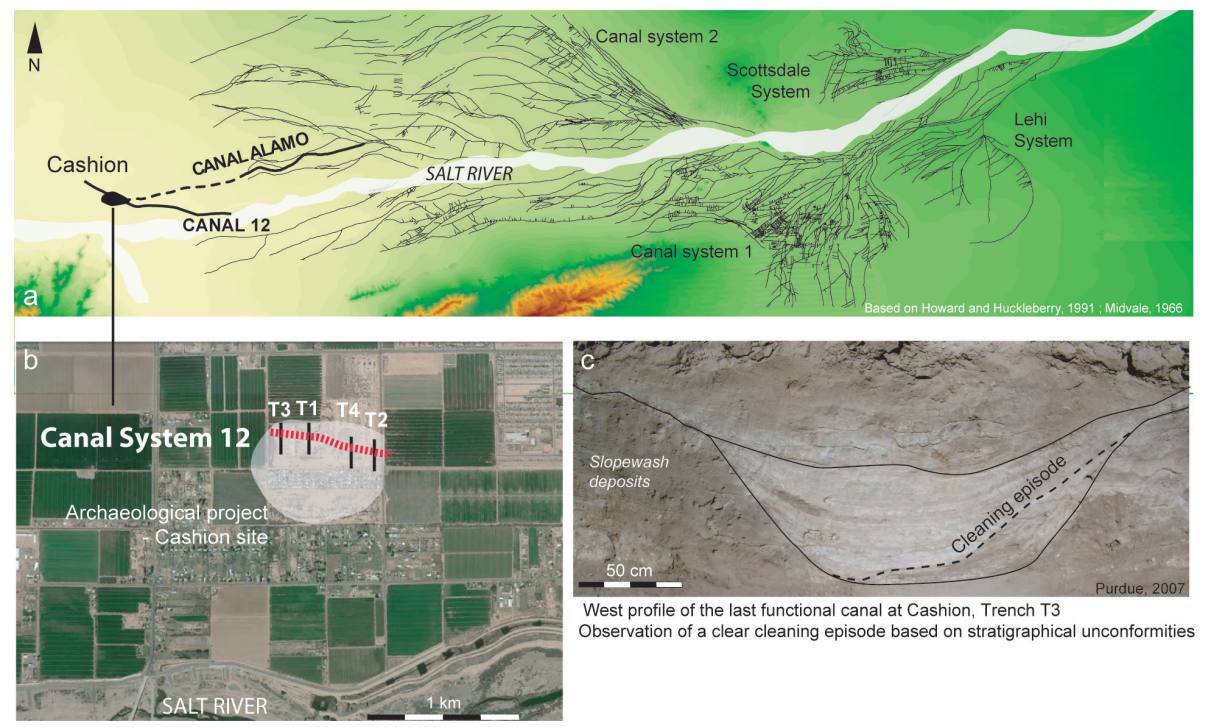

Fig. 5. (a) Irrigation systems along the Lower Salt River valley (Phoenix, Arizona) with location of Cashion site, (b) zoom on the spatial extension of the archaeological project with Canal System 12 and the four trenches dug perpendicular to the canals alignment (Google Earth, 2013), (c) photograph of the west profile of the upper and last canal in use. Note the stratigraphic unconformity that indicates a cleaning episode.

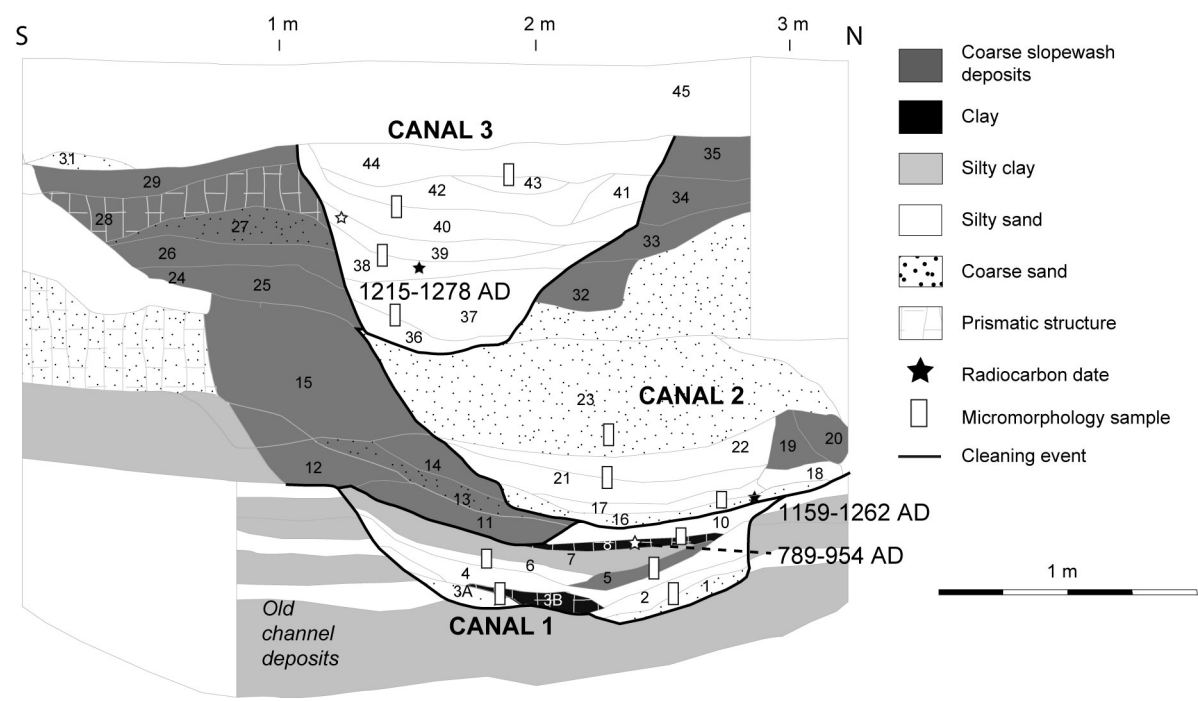

Fig. 6. Stratigraphic profile of Canal System 12 (Trench 1), chronology, and location of the soil micromorphological samples. CS12 was dug in an old channel and most of the sediments filling the three structures are laminated silts and sands, intertwined with slopewash deposits indicating rhythmic flow and temporary abandonment.

when a structure is continuously used, but when multiple episodes of cleaning are observed it is necessary to process as many dates as possible to frame these events. Archaeological material such as sherds identified can provide information on when the canal was in use. However, absolute dating (radiocarbon dating on organic material or Optical Luminescence Dating on quartz grains) (Berger et al., 2004; Huckleberry and Rittenour, 2013) should be preferentially used. Three radiocarbon dates were processed in Trench 1
(Fig. 6). Results show that the first canal was in use from the 8th to the 10th century AD, the second one from the mid12th century to the mid-13th century $\mathrm{AD}$, and the last one during the 13th century AD. Two phases of abandonment are recorded; one between the 10th and the 12th century $\mathrm{AD}$ and the second one, probably of much shorter time, during the 13 th century.

Micromorphology provides a description of soils at a very small scale using an optical polarized microscope. The aim 

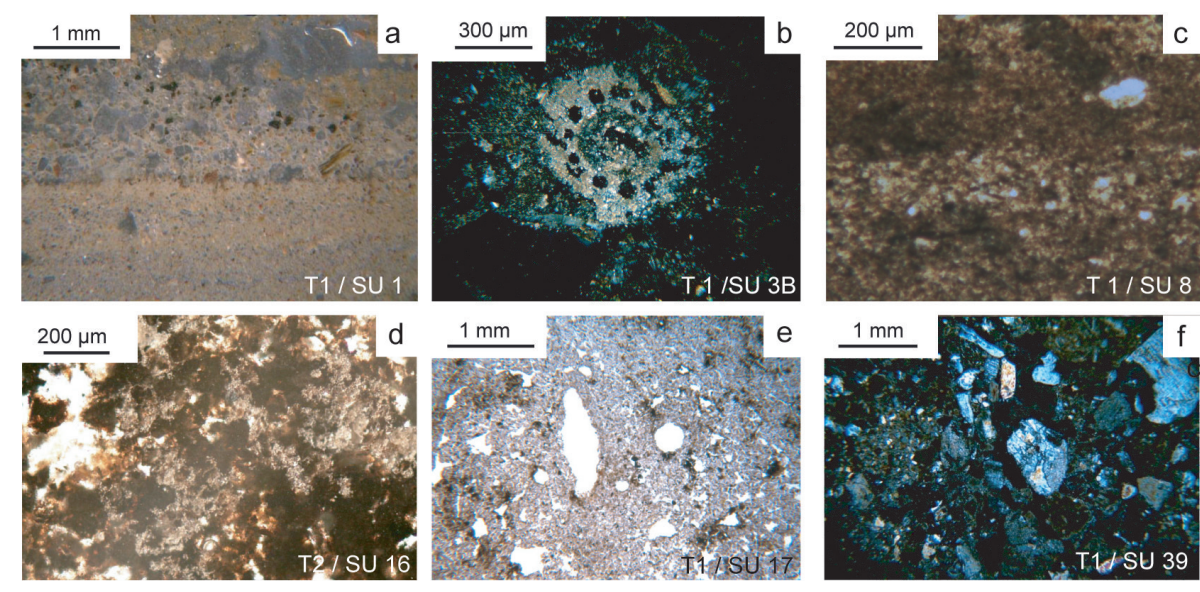

Fig. 7. Microphotographs of some short-term environmental and anthropic features identified in Canal System 12. PPL: plane polarized light, XPL: crossed polarized light, IL: incident light. (a) Graded silts rich in charcoal (IL); (b) transversal cross-cut of the stem of a characae (XPL); (c) mixed flaky burnt organic matter with particles of micrite calcium carbonate (ashes) indicating in situ burning (XPL); (d) collapsed structure as a results of moist conditions/vughy structure (PPL); (e) weakly sorted deposits composed of sand and rounded soil aggregates indicating erosional processes; (f) soil aggregates and the lack of soil development.

of this approach is to make precise observations made on the field and focus on a certain amount of well-preserved sedimentary, pedological, ecological and anthropic features which record short-term (sometimes seasonal) environmental and human dynamics (Courty et al., 1989). Samples were taken in both Trench 1 and 2 to compare and complete data (respectively 11 samples-33 microstrata, and 12 samples28 microstrata) (Fig. 6), and were processed at the University of Basse-Normandie-GEOPHEN (Caen, France). Analysis was conducted using a microscope connected to a color camera and we selected markers which were qualitatively, semiquantitatively and quantitatively described: (1) sedimentological markers (mineral assemblage to estimate sediment origin-fluvial or local; grain size; sediment structure and sorting to understand the flow and degree of erosion), (2) pedological and ecological markers (soil microstructure; in situ vegetation growth and its impact on sedimentation rhythm; in situ burning event) (Fig. 7). Each microstrata has its own short-term socio-environmental signature. However, for explanatory purposes, we will present results partially synthesized in 5 phases from Trench 1 , with a focus on specific markers of interest from Trench 1 and 2.

The first three phases have been identified in the first canal. Phase 1 (Stratigraphic Unit-SU 1-5 in T 1) (Fig. 6) is composed of positively graded clayey silts indicating rhythmic sedimentation of low intensity, possibly seasonal, with in and out flow maybe as a results of opening and closing head gates (Fig. 7a, SU 1). The in situ development of characeae communities (Fig. 7b, SU 3b) confirms the low flow and indicates clear as well as shallow water depth. The second period (SU 6-7 in T 1) is also composed of positively graded deposits, but the occurrence of coarse silts and sands indicate higher intensity flows. The impact of this shift is visible by the eroded berm deposits in $\mathrm{T} 2$ followed by canal cleaning. Canal maintenance also occurred as shown by the ash deposits in $\mathrm{T} 1$ (SU 7) indicating in situ burning to destroy the vegetation.

The third period (SU 8-10 in T $1 ; 8-9$ th century AD) is composed of prismatic clay and graded clayey silts (Fig. 6c, SU 8), rich in humic organic matter and charcoals, indicating episodes of rhythmic but low flow, water stagnation and evaporation processes. Eolian sand has been encountered in T 2 which could point towards drier conditions. The canal then seems abandoned up until the mid-12th century and filled with slope wash deposits and trash (observation of pluricm calcium carbonate nodules from the substratum; charcoals, ashes, organic matter and calcium oxalate crystals usually found in local vegetation which points toward dumped food remains in T 2) (Fig. 7d, SU 16). We put forward that the abandonment of the canal could be the result of shifting hydrological dynamics (e.g., down-cutting event) (Phillips et al., 2004; Purdue, 2011; Huckleberry et al., 2013).

The second major canal (Period 4, SU 16-23 in T 1), identical in size to the first one, was in use between the 12th and 13th century AD. Coarse silts rich in charcoal and presenting a massive to vughy structure indicate fast sedimentation as well as permanent moist conditions (Fig. 7e, SU 17). The layer of ashes in T 2 and the earth protection on the side of the feature in $\mathrm{T} 1$ (SU 18, 19, 20) suggests canal maintenance, but no visible cleaning event has been recorded. The bioturbated structure in the upper part of the feature (SU 23), as well as the in situ development of vegetation indicates reduced flow and even canal abandonment, contemporaneously to the abandonment of Cashion site. However, a third canal seems to have been built; it was connected to the tail of a 
canal belonging to Canal System 2, Canal Alamo (Fig. 7a). In use during the 13th century, this canal is much smaller in size and is filled with graded as well as weakly sorted coarse silts to sands. The occurrence of soil aggregates and the lack of soil development is an indicator of fast sedimentation, contrasted conditions (rhythmic sedimentation versus possible flooding events) and soil erosion during that period (Fig. 7f, SU 39). The canal is cleaned at least once. Its upper part is composed of coarse silts with a sub-angular structure suggesting post-abandonment flood deposits.

This detailed analysis suggests that the fill of CS12 is mainly characterized by rhythmic deposition, despite it being the most downstream system in the lower Salt River valley, with low flows around the 8-9th century AD, and more intense and erosive flows between the 12th and 13th century AD. Two interesting events have been recorded. The first one is the canal abandonment during the Sedentary Period, when massive flooding, widening and down-cutting occurred in the lower Salt River valley (Purdue, 2011; Phillips et al., 2004; Onken et al., 2004; Huckleberry et al., 2013). The second one is its connection to Canal System 2 after that, suggesting difficulties in diverting water in downstream systems, but cooperation to actually connect independent irrigation systems. The observation of ash deposits, cleaning events and lateral protection structure were part of the regular maintenance. From a methodological standpoint, the geo-archaeological approach provides very precise information on short-term to middle-term environmental conditions in past irrigation canals. This information can help to conduct better simulations on irrigation system management (e.g., change in slope through time; evolution of flow in main, distribution and lateral canals; irrigation management in fields). Systematic studies allow for the creation of a typology of canal fills and will provide local to regional data to help validate agent-based models.

\section{Reconstructing irrigation at Las Capas: the short-term view}

Our short-term example is the site of Las Capas, situated along the Santa Cruz River, a tributary of the Gila River, in modern Tucson. Las Capas is earlier than the far larger irrigation works to the north along the Salt and Gila rivers. Occupied from about $2100 \mathrm{BCE}$ until perhaps $500 \mathrm{BCE}$ (Mabry, 2008a), the site is noteworthy for its remarkable preservation: flood events deposited layers of silt that sealed some occupation layers and preserved them with minimal disturbance (Wöcherl, 2008). One set of excavations conducted by Desert Archaeology, Inc. (Mabry, 2008b; Vint, 2009) has revealed a detailed picture of irrigation structures, fields, and even individual planting holes; this rich picture also includes construction techniques: lateral canals and field berms were constructed by digging sediment from either side and piling
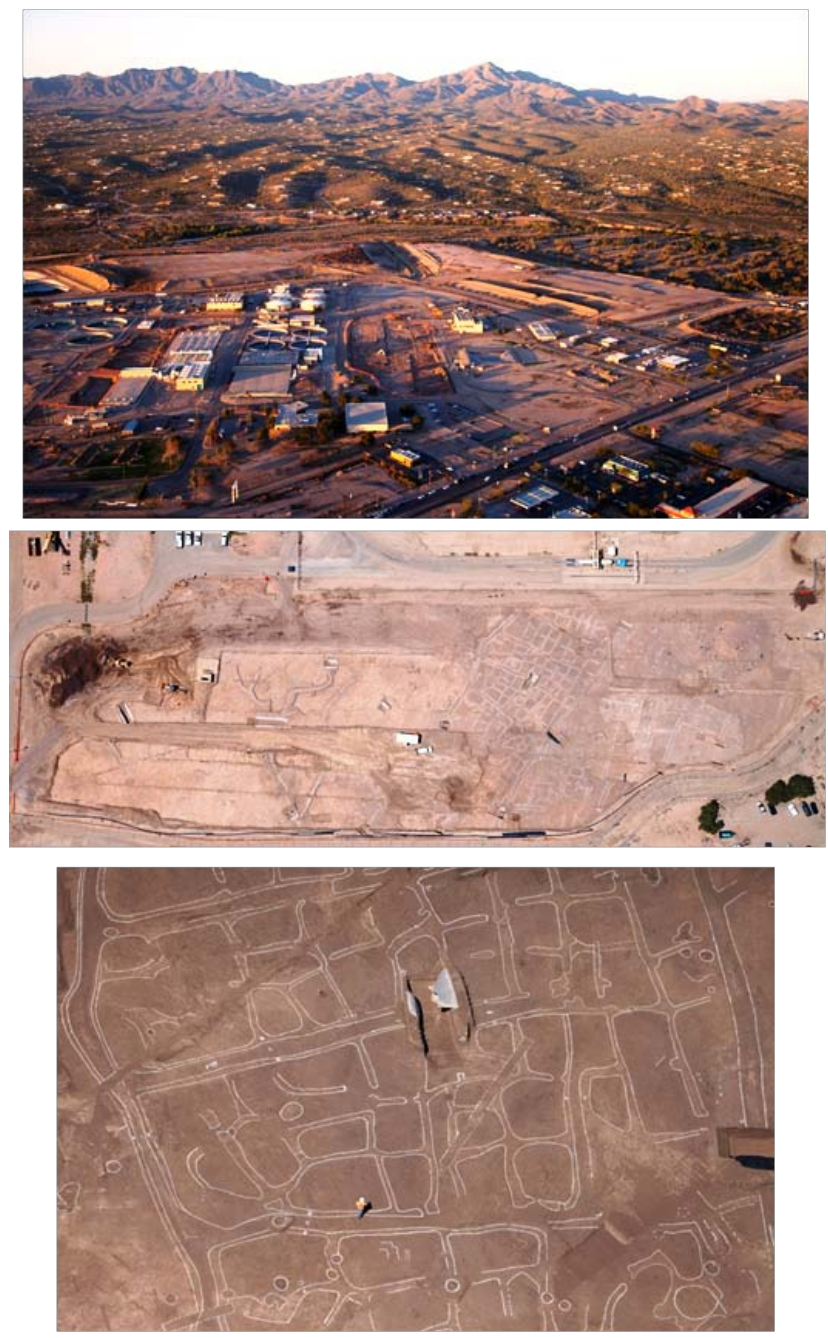

Fig. 8. Impressions of the site of Las Capas. Top panel: overview; middle panel: areal overview; bottom panel: detail of fields. Photos by Henry D. Wallace, Desert Archaeology, Inc.

the dirt to create banks and field boundaries (J. Vint, personal communication, 2013).

Figure 8 shows the site's location alongside the Tucson Mountains and the Santa Cruz River, and the reconstruction, in white paint, of the outlines of fields and canals visible to archaeologists. Figure 9 shows a drawing of the canals and fields found, dating from roughly $900 \mathrm{BC}$ to between 800 and $750 \mathrm{BC}$. This detail allows construction of water flow simulations at the day-to-day scale in a way that previous examinations of larger canals have not done. Based on available data, a model setup was designed with the SOBEK Hydraulic Modeling package (2014) with one canal (called feeder in this simulation although it is fairly small), seven lateral canals and four fields per lateral (Fig. 10). At Las Capas the larger distribution canals average $1.2 \mathrm{~m}$ wide and 0.23 to $0.30 \mathrm{~m}$ deep and have a parabolic cross section yielding a functional water depth of 0.20 to $0.25 \mathrm{~m}$. The lateral canals 


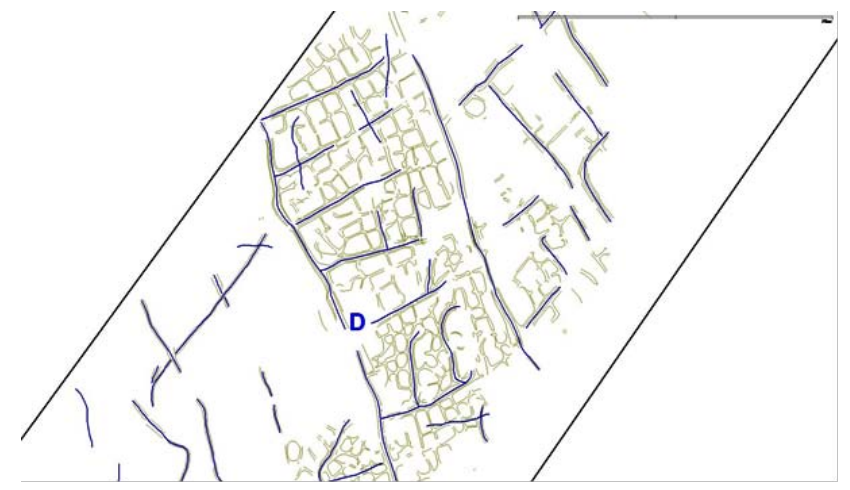

Fig. 9. The irrigation system (blue lines $=$ canals; scale $=70 \mathrm{~m}$; image courtesy of Desert Archaeology, Inc.).

at Las Capas average $1.0-1.1 \mathrm{~m}$ wide and $0.15 \mathrm{~m}$ deep, with a functional water depth of ca. $5 \mathrm{~cm}$ (J. Vint, personal communication, 2013).

The canals in the model have a bed width of $0.8 \mathrm{~m}$, a side slope of 1 and a design water depth of 0.20 , which yields a width at the design water level of $1.2 \mathrm{~m}$. Fields at Las Capas are small, approximately 5 by 5 to 10 by $10 \mathrm{~m}$, and are bounded by berms circa $10-15 \mathrm{~cm}$ high (J. Vint, personal communication, 2013). In the model, fields are modeled with dimensions 10 by $15 \mathrm{~m}$ (each representing several smaller fields) with a design water depth of $10 \mathrm{~cm}$. Several water control scenarios were tested, after confirming that without control water availability in the downstream areas of the system - both in the feeder as along laterals - would be insufficient to reach the required $10 \mathrm{~cm}$ of water depth on every field. Controls were modeled as weirs of $1 \mathrm{~m}$ width that could be opened or closed depending on the control action.

What type of control structures were used to manipulate flows in such irrigation systems is actually still a question. One would expect that structures of mud and wood would have been used, and these materials leave few archaeological traces. Today, only a few partially preserved control gates have been encountered in the Hohokam world and their systematic use has not yet been proven. One purpose of our study is to understand how such features could have been used in the first place, and what advantages they would offer. The same remark can be made for the social organization of irrigation. This issue is actually germane to our main point for this section: although evidence is available on the general Hohokam society, the details of its water management are unknown, and we hope to comprehend it better by understanding the constraints of the physical system, which is what we are modeling. Our modeling is obviously based on archaeological evidence, but also points out the need to search for other types of archaeological evidence (including control structures).

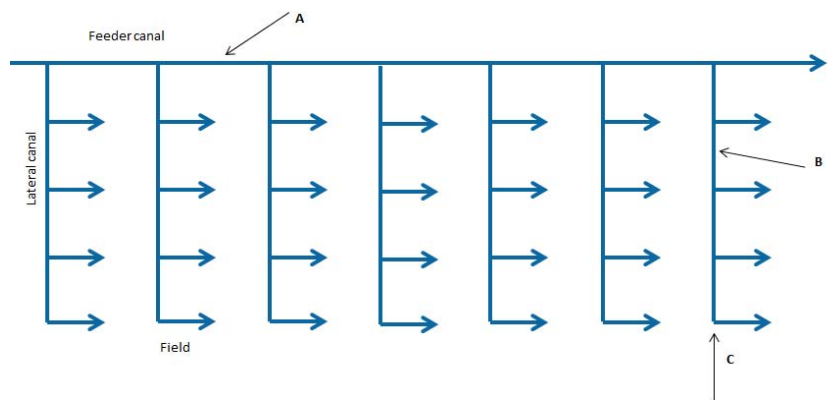

Fig. 10. Schematic of the model, with one feeder canal, 7 laterals and 28 fields (A, B and C are explained in the text).

Typically, a control action was defined as "move the weir once in the target field a water depth of $10 \mathrm{~cm}$ is reached". Control could be on three levels:

- Feeder level (A in Fig. 10): all the water moves to the lateral, and only if all fields along the lateral have water depths of $10 \mathrm{~cm}$ is water allowed to flow along the feeder to the next lateral.

- Lateral level (B in Fig. 10): all the water moves to one field along the lateral, and only if that field has a water depth of $10 \mathrm{~cm}$ is water allowed to flow along the lateral to the next field.

- Field level (C in Fig. 10): fields are closed once a water depth of $10 \mathrm{~cm}$ is reached.

Control actions were tested on their own and in combinations. Six scenarios were tested, with five (Tables 1 and 2) starting irrigation upstream in the system working their way down. One scenario (Table 3) starts irrigating downstream and moves up. The model checked target levels every 4 minutes, representing expected continuous interaction between irrigators within a small area. Each control scenario was tested with two inflow scenarios. In the first, an upstream boundary condition is imposed with a constant flow depth of $20 \mathrm{~cm}$; this constant water depth represents an average inflow of 20 to $25 \mathrm{~L} \mathrm{~s}^{-1}$. In the second, fluctuating inflow is specified as an upstream boundary of changing water levels in random order; this order is the same for all scenarios.

The results per scenario were expressed in the time of arrival of water at the most downstream field for each lateral in hours (Tables 1 to 3). For those scenarios where fields could be closed after reaching the target water depth of $10 \mathrm{~cm}$, arrival and closing times per field were taken. Assuming a constant inflow of $20 \mathrm{~L} \mathrm{~s}^{-1}$ and a volume to be covered with $10 \mathrm{~cm}$ of water everywhere in the fields, total irrigation time (calculated simply by taking the total volume of water needed and dividing this by the delivery rate of $20 \mathrm{~L} \mathrm{~s}^{-1}$ ) would be a little less than $6 \mathrm{~h}$. Including the volume required to fill the canals as well adds another hour to the irrigation time. Therefore a total irrigation time of some $7 \mathrm{~h}$ for the 28 fields 
Table 1. Model results for control scenarios in canal system: water arriving at laterals after $\times \mathrm{hr} \mathrm{min}^{-1}$.

\begin{tabular}{|c|c|c|c|c|c|c|}
\hline \multirow{2}{*}{ Lateral } & \multicolumn{2}{|c|}{ Feeder (A) } & \multicolumn{2}{|c|}{ Feeder + lateral (A and B) } & \multicolumn{2}{|c|}{ Lateral (B) } \\
\hline & Steady & Fluctuating & Steady & Fluctuating & Steady & Fluctuating \\
\hline 1 & 0.23 & 0.46 & 0.42 & 1.46 & 0.43 & 1.51 \\
\hline 2 & 0.35 & 1.53 & 1.10 & 2.10 & 1.18 & 2.10 \\
\hline 3 & 1.09 & 2.10 & 1.51 & 5.15 & 2.19 & 5.30 \\
\hline 4 & 2.15 & 3.00 & 2.49 & 5.39 & 3.19 & 6.22 \\
\hline 5 & 3.14 & 6.18 & 3.48 & 7.15 & 4.15 & 7.11 \\
\hline 6 & 4.25 & 7.20 & 4.55 & 8.07 & 5.01 & 7.59 \\
\hline 7 & 5.40 & 8.40 & 6.19 & 9.35 & 5.37 & 8.36 \\
\hline
\end{tabular}

Table 2. Model results for field control scenarios: water arriving at laterals after $\times \mathrm{h} \min ^{-1}$.

\begin{tabular}{|c|c|c|c|c|c|c|c|c|}
\hline \multirow{3}{*}{ Lateral } & \multicolumn{4}{|c|}{ Feeder + field (A and C) } & \multicolumn{4}{|c|}{ Full (A, B and C) } \\
\hline & \multicolumn{2}{|c|}{ Steady } & \multicolumn{2}{|c|}{ Fluctuating } & \multicolumn{2}{|c|}{ Steady } & \multicolumn{2}{|c|}{ Fluctuating } \\
\hline & Start & End & Start & End & Start & End & Start & End \\
\hline 1 & 0.21 & 0.54 & 0.42 & 0.57 & 0.45 & 1.45 & 1.38 & 1.49 \\
\hline 2 & 0.34 & 1.21 & 1.06 & 1.25 & 1.50 & 3.17 & 2.06 & 3.12 \\
\hline 3 & 1.04 & 1.53 & 1.43 & 2.05 & 2.06 & 5.05 & 4.54 & 5.17 \\
\hline 4 & 1.48 & 2.37 & 2.27 & 2.49 & 2.41 & 5.21 & 5.23 & 5.49 \\
\hline 5 & 2.33 & 3.25 & 3.23 & 3.49 & 5.39 & 6.29 & 6.15 & 6.41 \\
\hline 6 & 3.22 & 4.17 & 3.59 & 4.29 & 6.15 & 7.09 & 7.11 & 7.37 \\
\hline 7 & 4.17 & 5.09 & 4.48 & 5.13 & 7.17 & 8.09 & 7.59 & 8.21 \\
\hline
\end{tabular}

Table 3. Model results for downstream control scenarios: water arriving at laterals after $\times \mathrm{h} \min ^{-1}$.

\begin{tabular}{llllll}
\hline & \multicolumn{3}{c}{ Downstream feeder } \\
\cline { 2 - 3 } Lateral & \multicolumn{2}{c}{ Steady } & & \multicolumn{2}{c}{ Fluctuating } \\
\cline { 2 - 3 } \cline { 5 - 6 } & Start & End & & Start & End \\
\hline 1 & 5.27 & 5.45 & & 8.07 & 8.29 \\
2 & 4.50 & 5.13 & & 7.40 & 8.09 \\
3 & 4.08 & 4.33 & & 7.11 & 7.37 \\
4 & 3.26 & 3.49 & & 6.30 & 6.53 \\
5 & 2.35 & 3.05 & & 5.39 & 6.09 \\
6 & 1.45 & 2.13 & & 4.04 & 5.17 \\
7 & 0.39 & 1.21 & & 1.33 & 3.17 \\
\hline
\end{tabular}

is a useful baseline. When irrigation times become longer as in many of our simulations - the total volume delivered to the system as a whole becomes higher - part of it leaves the canals as drainage water - suggesting that keeping irrigation time to a minimum improves effectiveness of water use. However, within larger irrigated areas, benefits of time and volume saving on smaller scales are closely related to larger scale dynamics - an issue we will return to below.

The modeling setup was obviously very basic and we should not draw anything more than preliminary conclusions based on a comparison between the scenarios, but nevertheless some first remarks can be made upon which directions for further study can be defined. First, a baseline order of magnitude calculation is in order. Tables 1-3 show that when applying control, total irrigation times for these 28 fields were on the order of $6 \mathrm{~h}$. The results also suggest that fluctuations in inflow appear to have a large impact on total irrigation time and can bring total time up to almost $10 \mathrm{~h}$. This suggests that one needs to be able to position a smallscale system like this within its larger spatial context. An issue to study further would be whether in systems like these fluctuations - if present - were caused mainly by changing natural inflows or by human agency elsewhere in the irrigated area.

The three scenarios controlling water flows on canal level only (Table 1) do not yield very different results. All three controls - on feeder, lateral or both - need something like 6 hours with steady inflow and some $3 \mathrm{~h}$ more with fluctuating inflow. However, control in the canals combined with control of fields (Table 2) results in some different results. Both scenarios in this category keep irrigation times for steady and fluctuating inflow more or less stable. However, full control of flows - water is only allowed to flow to a next field and/or canal once a field has reached target water level - appears to result in larger irrigation times compared to a control scenario where only inflow into laterals and fields is controlled. An explanation may be that with full control it 
takes time for the water to reach enough head. These results may indicate that it is favorable in terms of irrigation times to irrigate a field and bring water further downstream even when a field upstream has not reached its target level yet. If this is correct - and not a creation of the modeling setup too much - the hydraulic characteristics of the control scenario may ease the need for full coordination between fields and irrigators. It is also an indication that the canals are large compared to the fields.

In some irrigation systems, the order of irrigation is occasionally turned around from the natural preferential situation of gravity in the sense that downstream users are allowed to irrigate first before upstream users can do so. Our downstream-first scenario shows no clear differences from the upstream scenario. Irrigation times with fluctuations are actually much longer. On this scale, the order of irrigation seems to have less impact than the type of water control that is applied. Although these first results are preliminary, they indicate that coordination between laterals in terms of when to open and close them combined with individual decisions when to close fields after reaching a target water depth may have been the control scenario with higher benefits in terms of stability and lower demands in terms of coordinating actions required. Obviously, our simulation of 28 fields is a simplification of the archaeologically attested example with its more than 1000 fields. Nevertheless, we clearly show lower delivery times and greater stability under certain control scenarios. We cannot be certain that these differences in irrigation delivery times between scenarios would have translated into markedly different societal/individual benefits in our specific case, as we have not done this analysis yet. Such analysis would require using all the data sets we discussed in the paper. However, comparing our findings with irrigation systems in general suggests that it is beneficial to have stability and lower demands in terms of coordinating actions.

\section{The long and the short: which view to choose?}

The three views given here - long-term climatic reconstruction; middle-term pattern of canal construction, use, repair, and abandonment; and the short-term interplay of canal operation and management - are separate examples from times and places that are close to one another but cannot be fully integrated; we offer them instead as examples of the pictures of irrigation that archaeological studies can give. Our point, however, is that these three views, are not - and indeed cannot be - incompatible: in the real progress of events they all played out simultaneously. The daily management of fields was conducted within the larger context of which canals were operational, which were in need of repair, which had been abandoned but could be reused, and whether new canals were needed. This, in turn, played out against a longer backdrop of shifting water supply: solutions that made sense when wet years were rare might be less useful when wet years were more common, and the search for the best solution meant chasing nature's moving target. All of these components are revealed through archaeological means; the picture is broken and incomplete across time and space, but as more data are acquired and organized it fills in and sharpens.

Our question here is whether the modeling effort can select the appropriate scale at which to approach the dynamics under study. Murphy (2009) has shown that a simple interaction between upstream and downstream field systems both drawing from a single water source can lead to complex dynamics that, in turn, might be deeply shaped by water supply, and thus be markedly different in wet vs. dry years; this kind of game in turn would have impacted the way that the fields were fed, changing the hydraulic dynamics, which would presumably have impacted the social dynamics among the field managers. If, as the simulations described here show, different patterns of filling fields lead to different efficiencies, then the negotiations of how the fields were watered - the perennial questions of who gets the water when - would have been affected as well. The middle-term shifts in infrastructure would have meant that no solution would have served permanently.

This integrated picture argues for a modeling effort that begins with the input data provided by medium- and longterm views, but that specifically uses these to address the small scale: the formal and informal institutions that we believed would have maintained these systems would have grown out of the shifting dynamics at the tightest scales. Our modeling must capture this. From this we can hope to apply the lessons gained from the long-term archaeological record to the present, where the day-to-day scale is, of course, far more salient. With the objective of better understanding human agency through modeling, this paper puts forward the relevance of combining hydrological, geographical, archaeological, and social studies when studying water systems. Human agency articulates itself around short-term socioenvironmental dynamics as agents and networks continuously interact. Similar concepts related to the co-evolution of humans and their environment has been developed by other disciplines and the importance of pluri-disciplinary approaches is not new. However, crossing disciplinary and methodological barriers is not easy. On the other hand, the rapid development of agent-based modeling, which aims to understand human behaviors, opens new research perspectives and requires inter-disciplinarity. Because we argue that models rely on a bottom-up principle, they need to be supplied and validated by observed data from various fields of research. Therefore, data on irrigation management, hydrology and high-resolution soil data will provide a relevant basis for modeling.

This type of socio-hydrology recognizes that organisms like humans change their environment; the famous beavers build dams, termites build huge mounds. On its own turn, environment changes organisms; selective pressures from an environment have an influence on survival strategies of 
those living within that environment (Nelson et al., 2010). Such a process of niche construction (Kendall et al., 2011) includes the bidirectional nature of interactions between material environment and social arrangements, in order to capture how humans change their environment, and how subsequent environmental changes alter societal functioning. This calls for many more studies providing empirical evidence for co-evolving social/economic and environmental systems - e.g., studies that take a historical or archaeological approach, or use social science methods to assess how communities/societies create and respond to environmental change.

The full approach that we envision, one that places agentbased models in simulations that can integrate data from a range of disparate sources and explore alternatives at a range of scale, is not yet developed. The software, and the scientific strategy for using such software, remain possibilities but are not yet complete. Our concern is that traditional approaches to modeling human social action in social-ecological contexts avoid the central issues of human agency; our hope is that future examples will build on the position here, and the goal of understanding how human agency shapes relationships and institutions in contexts such as irrigation will soon be within our reach.

Acknowledgements. Authors would like to thank the School of Human Evolution and Social Change and well as the School of Sustainability at Arizona State University (Tempe, Arizona) for their support in the collection of the data. Louise Purdue would also like to thank Soil System Inc. (Paleowest) and the GEOPHEN laboratory (University of Caen Basse-Normandie, France) for the support they provided in collecting and preparing the data as well as the Fyssen Foundation for its financial support in the development of this project. Fieldwork at the Las Capas site in 2008 and 2009 was undertaken by Desert Archaeology, Inc, and was funded by Pima County, Arizona, bonds as part of the Ina Road Regional Wastewater Reclamation Facility Upgrade Project. All photos and source data are courtesy of Desert Archaeology, Inc., Tucson, Arizona, and we gratefully acknowledge the opportunity to work with the data their excavations have collected and the effort they made in providing the data in a useful format. Special thanks are due to Desert Archaeology's James Vint and Fred Nials; without their contributions of materials, data, and insight this project would not have been possible. All errors are our own.

Edited by: M. Sivapalan

\section{References}

Altaweel, M.: Investigating agricultural sustainability and strategy in Northern Mesopotamia: Results produced using a socioecological modeling approach, J. Archaeol. Sci., 35, 821-835, 2008.

Bayman, J.: The Hohokam of Southwest North America, J. World Prehist., 15, 257-311, 2001.
Berger, G. W., Henderson, T. K., Banerjee, D., and Nials, F. L.: Photonic dating of prehistoric irrigation canals at Phoenix, Arizona, U.S.A., Geoarchaeology, 19, 1-19, 2004.

Berger, J.-F.: Les fossés bordiers historiques et l'histoire agraire rhodanienne, Etudes rurales, La très longue durée, 153-154, 59_ 90, 2000.

Chen, J., Brissette, F. P., and Leconte, R.: Uncertainty of downscaling method in quantifying the impact of climate change on hydrology, J. Hydrol., 401, 190-202, 2011.

Courty, M. A., Goldberg, P., and Macphail, R. I.: Soils and micromorphology in archaeology. Cambridge Manuals in Archaeology, Cambridge University Press, Cambridge, 1989.

Ertsen, M. W.: Structuring properties of irrigation systems, Understanding relations between humans and hydraulics through modeling, Water History, 2, 165-183, 2010.

Ertsen, M. W.: Modelling human agency in ancient irrigation, in: XXXIIe rencontres internationales d'archéologie et d'histoire d'Antibes "Variabilites environnementales, mutations sociales? Nature, Intensités, Échelles et Temporalités des changements", edited by: Bertoncello, F. and Braemer, F., Antibes, 199-209, 2012a.

Ertsen, M. W.: Irrigation and landscape: an interdisciplinary approach, in: Landscape Archaeology between Art and Science - From a multi- to an interdisciplinary approach, Landscape \& Heritage Series, edited by: Kluiving, S. J. and GuttmannBond, E. B., Amsterdam University Press, Amsteredam, 45-58, 2012b.

Ertsen, M. W. and Van der Spek, J.: Modeling an irrigation ditch opens up the world. Hydrology and hydraulics of an ancient irrigation system in Peru, Phys. Chem. Earth, 34, 176-191, 2009.

Fish, P. R.: The Hohokam: 1,000 Years of Prehistory in the Sonoran Desert, in: Dynamics of Southwest Prehistory, edited by: Cordell, L. S. and Gumerman, G. J., Smithsonian Institution Press, Washington, D.C., 19-63, 1989

Fish, S. K. and Fish, P. R. (Eds.): The Hohokam Millennium, in: The Hohokam Millennium, School for Advanced Research Press, Santa Fe, New Mexico, 1-11, 2007.

Gentelle, P.: Le Croissant Fertile, Le monde de la Bible et Terre Sainte, 15, 4-8, 1980.

Graybill, D. A., Gregory, D. A., Funkhouser, G. S., and Nials, F. L.: Long-term streamflow reconstructions, river channel morphology, and aboriginal irrigation systems along the Salt and Gila Rivers, in: Environmental change and human adaptation in the ancient Southwest, edited by: Dean, J. S. and Doyel, D. E., University of Utah Press, Salt Lake City, 69-123, 2006.

Gumerman, G.: Understanding the Hohokam, in: Exploring the Hohokam, Prehistoric desert peoples of the American Southwest, edited by: Gumerman, G. J., University of New Mexico Press, Albuquerque, 1-27, 1991.

Howard, J. B.: A Paleohydraulic Approach to Examining Agricultural Intensification in Hohokam Irrigation Systems, Res. Econ. Anthropol., 7, 263-324, 1993.

Howard, J. B. and Huckleberry, G.: The operation and evolution of an irrigation system: the East Papago Canal study, Publication no. 18, Soil Systems Publication in Archaeology, Phoenix, 1991.

Huckleberry, G.: Stratigraphic identification of destructive floods in relict canals: a case study from the Middle Gila River, Arizona, the Kiva, Kiva, 65, 7-33, 1999. 
Huckleberry, G. and Rittenour, T.: Combining radiocarbon and single-grain optically stimulated luminescence methods to accurately date pre-ceramic irrigation canals, Tucson, Arizona, J. Archaeol. Sci., 41, 156-170, 2013.

Huckleberry, G., Onken, J., Graves, W., and Wegener, R.: Climatic, geomorphic, and archaeological implications of a late Quaternary alluvial chronology the lower Salt River, Arizona, USA, Geomorphology, 185, 39-53, 2013.

Hunt, E. and Hunt, R. C.: Irrigation, conflict, and politics: a Mexican case, in: Irrigation's impact on Society, edited by: Downing, T. and MacGuire, G., University of Arizona Press, Tucson, 129157, 1973.

Kendal, J., Tehrani, J. J., and Odling-Smee, F. J.: Human niche construction in interdisciplinary focus, Philos. T. Roy. Soc. B, 366, 785-792, 2011.

Kohler, T. A. (Ed.): Modeling Agricultural Productivity and Farming Effort. In Emergence and Collapse of Early Villages: Models of Central Mesa Verde Archaeology, University of California Press, Berkeley, Los Angeles, 2012.

Latour, B.: Reassembling the Social: An Introduction to Actor Network Theorym, Oxford University Press, Oxford, 2005.

Mabry, J. B.: Chronology, in: Las Capas: Early Irrigation and Sedentism in a Southwestern Floodplain, Anthropological Papers 28, Center for Desert Archaeology, Tucson, 55-76, $2008 \mathrm{a}$.

Mabry, J. B. (Ed.): Las Capas: Early Irrigation and Sedentism in a Southwestern Floodplain, Anthropological Papers No. 28, Center for Desert Archaeology, Tucson, 2008b.

Midvale, F.: The Prehistoric irrigation of the Salt River valley, 4th Edn., Map on file, Department of Anthropology, Arizona State University, Tempe, 1966.

Murphy, J. T.: Exploring Complexity in the Past: The Hohokam Water Management Simulation, PhD Dissertation, Department of Anthropology, University of Arizona, Tucson, 2009.

Murphy, J. T.: Exploring complexity with the Hohokam Water Management Simulation: A middle way for archaeological modeling, Ecol. Modell., 241, 15-29, 2012.

Nelson, M. C., Kintigh, K., Abbott, D. R., and Anderies, J. M.: The cross-scale interplay between social and biophysical context and the vulnerability of irrigation-dependent societies: archaeology's long-term perspective, Ecol. Soc., 15, 31, 2010.

Ni, F., Cavazos, T., Hughes, M. K., Comrie, A. C., and Funkhouser, G.: Cool-season precipitation in the southwestern USA since AD 1000: comparison of linear and nonlinear techniques for reconstruction, Int. J. Climatol., 22, 1645-1662, 2002.
Onken, J., Waters, M. R., and Homburg, J. A.: Geoarchaeological assessment for the Tres Rios Project, Maricopa County, Arizona, Technical Report 03-68, Statistical Research Inc., Redlands, California, 2004.

Pande, S. and Ertsen, M.: Endogenous change: on cooperation and water in ancient history, Hydrol. Earth Syst. Sci. Discuss., 10, 4829-4868, doi:10.5194/hessd-10-4829-2013, 2013.

Phillips, B. G., Gibbson, A., Miller, A., Droz, M. S., and Walker, L. A.: Paleoenvironnement, in: Life on the Lehi terrace: the archaeology of the Red Mountain Freeway between State Route 87 and Gilbert road, Archaeological Consulting Services Cultural Resources Report 135, edited by: Powell, S. and Boston, R. L., Archaeological Consulting Services, Tempe, 11-47, 2004.

Purdue, L.: Dynamique des paysages agraires et gestion de l'eau dans le bassin semi-désertique de Phoenix, Arizona de la Préhistoire à l'époque modern, Unpublished Ph.D. doctoral in Environmental Archaeology, University of Nice Sophia Antipolis, France, 2011.

Purdue, L., Miles, W., Woodson, K., Darling, A., and Berger, J.-F.: Micromorphological study of irrigation canal sediments: landscape evolution and hydraulic management in the middle Gila River valley (Phoenix Basin, Arizona) during the Hohokam occupation, Quatern. Int., 216, 129-144, 2010.

Purdue, L., Miles, W., Wright, D., Palacios Fast, M., Phillips, B., and Woodson, K.: Prehistoric agrosystems of Central Arizona: a paleoenvironmental approach to the study of Hohokam irrigated fields and canals, in preparation, 2014.

Salzer, M. W. and Kipfmueller, K. F.: Reconstructed temperature and precipitation on a millennial timescale from tree-rings in the Southern Colorado Plateau, USA, Climatic Change, 70, 465487, 2005.

SOBEK Hydraulic Modeling package: http://www.deltaressystems. com/hydro/product/108282/sobek-suite (last access: 12 November 2013), 2014.

Vint, J. B.: Completion of Compliance-related Archaeological Fieldwork at the Site of Las Capas (AZ AA:12:111 [ASM]) and Related Canals (AZ AA:12:753 [ASM]) on the Grounds of the Ina Road Regional Wastewater Reclamation Facility, Pima County, Arizona, MS on file at Desert Archaeology Inc., Tucson, Arizona, 2009.

Wöcherl, H.: Natural Site Formation Processes and Archaeological Interpretation, in: Las Capas: Early Irrigation and Sedentism in a Southwestern Floodplain, Anthropological Papers No. 28, Center for Desert Archaeology, Tucson, 77-94, 2008. 